\title{
Circadian sleep/wake-associated cells show dipeptide repeat protein aggregates in C9orf72-related ALS and FTLD cases
}

\author{
Lieselot Dedeene ${ }^{1,2,3,4^{*}}$ (D), Evelien Van Schoor ${ }^{2,4}$, Rik Vandenberghe ${ }^{5,6}$, Philip Van Damme ${ }^{4,5 \dagger}$, Koen Poesen ${ }^{1,3 \dagger}$ and \\ Dietmar Rudolf Thal ${ }^{2,7^{*+}}$
}

\begin{abstract}
Motor-, behavior- and/or cognition-related symptoms are key hallmarks in patients with amyotrophic lateral sclerosis (ALS) and frontotemporal lobar degeneration (FTLD) with TDP-43 pathology (FTLD-TDP), respectively. It has been reported that these patients also experience sleep disturbances, which might implicate a disturbed circadian rhythm of the sleep/wake cycle. It remains unknown, however, whether cells involved in the circadian sleep/wake cycle are affected by ALS- and FTLD-related neuropathological changes including phosphorylated TDP-43 (pTDP-43) aggregates and dipeptide repeat protein (DPR) inclusions resulting from the C9orf72 hexanucleotide repeat expansion. Immunohistochemistry for DPR and PTDP-43 pathology was performed in post-mortem hypothalamus and pineal gland tissue of patients with ALS and/or FTLD-TDP with and without the C9orf72 repeat expansion and healthy controls. Circadian sleep/wake-associated cells, including pinealocytes and hypothalamic neurons related to the suprachiasmatic nucleus (SCN), were microscopically assessed. We observed numerous DPR inclusions (poly(GA), poly(GP), poly(GR) and poly(PR)) in the pinealocytes and few poly(GA) inclusions in the SCN-related neurons in C9orf72-related ALS and/or FTLD-TDP cases. These circadian sleep/wakeassociated cells, however, were devoid of pTDP-43 pathology both in C9orf72- and nonC9orf72-related ALS and/or FTLDTDP cases. Our neuropathological findings show that pinealocytes and, to a lesser extent, SCN-related neurons are affected by DPR pathology. This may reflect an involvement of these cells in sleep/wake disturbances observed in ALS and/or FTLD-TDP patients.
\end{abstract}

Keywords: Amyotrophic lateral sclerosis, Frontotemporal dementia, C9orf72, Dipeptide repeat proteins, TDP-43, Pineal gland, Circadian rhythm, Sleep/wake cycle

\section{Introduction}

The hexanucleotide (GGGGCC) repeat expansion in the chromosome 9 open reading frame 72 (C9orf72) gene is the underlying genetic cause in approximately half of the familial amyotrophic lateral sclerosis (ALS) cases and in about $10 \%$ of the sporadic ALS cases [18]. Moreover, this C9orf72 repeat expansion connects ALS to frontotemporal lobar degeneration with

\footnotetext{
* Correspondence: lieselot.dedeene@kuleuven.be; dietmar.thal@kuleuven.be ${ }^{\dagger}$ Philip Van Damme, Koen Poesen and Dietmar Rudolf Thal contributed equally to this work.

'Department of Neurosciences, Laboratory for Molecular Neurobiomarker Research, KU Leuven (University of Leuven), Leuven Brain Institute (LBI), Leuven, Belgium

${ }^{2}$ Department of Imaging and Pathology, Laboratory for Neuropathology, KU Leuven (University of Leuven), Leuven Brain Institute (LBI), Leuven, Belgium Full list of author information is available at the end of the article
}

transactive response DNA-binding protein $43 \mathrm{kDa}$ (TDP-43) pathology (FTLD-TDP) by representing a quarter of the familial FTLD cases [34]. Patients carrying this C9orf72 repeat expansion show aberrant protein aggregates in neurons. These protein aggregates represent, on the one hand, dipeptide repeat proteins (DPRs) arising from unconventional repeat-associated non-ATG translation of the C9orf72 repeat expansion and, on the other hand, TDP-43, a nuclear protein, which is mislocalized to the cytoplasm [30,31]. Apart from symptoms related to the loss of both upper and lower motor neurons, it has been reported that patients with ALS also experience a disturbed sleep pattern, daytime sleepiness and fatigue [1, 9, 20, 24, 25]. These sleep-related symptoms are still underdiagnosed and are mainly considered as a consequence of muscle

(c) The Author(s). 2019 Open Access This article is distributed under the terms of the Creative Commons Attribution 4.0 International License (http://creativecommons.org/licenses/by/4.0/), which permits unrestricted use, distribution, and 
weakness and respiratory issues [39]. Patients with FTLD also show sleep/wake disturbances similar to sleep problems in patients with Alzheimer's disease (AD), although starting earlier in the disease course [2, 28]. One study showed a potential involvement of the C9orf72 repeat expansion in rapid eye movement sleep behavior disorder (RBD) by identifying two C9orf72 repeat expansion carriers in a cohort of 344 RBD patients [13]. Moreover, these two RBD patients were carriers of a risk haplotype associated with C9orf72-related ALS and FTLD [29]. This suggests that patients with ALS and/or FTLD-TDP carrying the C9orf72 repeat expansion could be more vulnerable to sleep abnormalities. Nevertheless, studies providing an in-depth characterization of the previously mentioned sleep problems in ALS and/or FTLD-TDP patients with and without the C9orf72 repeat expansion are yet to be performed.

In other neurodegenerative disorders, including $\mathrm{AD}$ and Parkinson's disease (PD), the sleep/wake cycle is disturbed along with changes in circadian melatonin levels $[6,38,40,42]$. Whether similar circadian rhythm disturbances are at the root of sleep problems in ALS and/or FTLD-TDP patients remains elusive $[1,24]$. In an $S O D 1^{\mathrm{G} 93 \mathrm{~A}}$ mouse model of ALS, artificially induced circadian rhythm dysfunction accelerated the disease onset as measured by motor function tests and disease progression in terms of body weight loss [22]. Moreover, this circadian rhythm dysfunction aggravated degeneration of motor neurons in the spinal ventral horn and increased astrocytic and microglial activation [22]. Furthermore, in an ALS/frontotemporal dementia (FTD) rat model bearing a FUS point mutation (R521C), the onset of cognitive deficits was preceded by circadian rhythm abnormalities and disturbances in the sleep/wake cycle [41]. Therefore, these findings point to the direction of circadian rhythm disturbances in ALS and FTD.

The two major brain structures regulating the circadian sleep/wake cycle are, on the one hand, the suprachiasmatic nucleus (SCN) ("the central biological clock") located in the hypothalamus and, on the other hand, the melatonin-producing pineal gland acting as the main executor of the SCN. The SCN suppresses or stimulates the pineal synthesis of melatonin according to the light/ dark cycle, leading to a decreased or increased tendency to sleep. In $\mathrm{AD}$ cases, neurofibrillary tangle pathology and plaques were observed in the SCN, but not in the pineal gland $[32,36]$. In PD cases, Lewy body pathology was observed in the SCN, and rarely in the pineal gland [17]. In ALS and/or FTLD-TDP patients, it remains unknown whether and, if so, which cells involved in the circadian sleep/wake cycle are affected by pathological changes. A better understanding of the underlying pathological mechanism of circadian sleep/wake disturbances may provide new insights in the involvement of this type of disturbances in the disease course of ALS and FTLD. To this end, we immunohistochemically investigated circadian sleep/wake-associated cells (i.e. the pineal gland and SCN-related neurons in the hypothalamus) for the presence of ALS- and FTLD-TDPrelated pathological protein inclusions (DPRs and phosphorylated TDP-43 (pTDP-43)) in patients with ALS and/or FTLD-TDP with and without the C9orf72 repeat expansion.

\section{Materials and methods}

\section{Human cases}

Post-mortem human brain tissue, including the pineal gland and hypothalamus, was provided by the UZ Leuven brain biobank (Belgium) and the municipal hospital Offenbach (Germany) in accordance with the Belgian and German law. This study was approved by the UZ Leuven ethical committee and the UZ Leuven biobank board. Table 1 shows the demographics and tissue availability of the human cases by study groups. A list of the individual human autopsy cases included in this study is provided in Additional file 1. In total, seven ALS and/or FTLD-TDP cases carrying the $C 9$ orf 72 hexanucleotide repeat expansion were included (4 ALS, 2 FTLD-TDP and 1 ALS-FTLD). They were further referred to as C9orf72 cases. The C9orf72 hexanucleotide repeat expansion was identified by triplet repeat primed PCR on DNA extracted from peripheral blood and/or cerebellum. As comparison for pTDP-43 pathology and as negative controls for DPR pathology, 21 ALS and/or FTLD-TDP cases without the C9orf72 hexanucleotide repeat expansion were included (11 ALS, 9 FTLDTDP and 1 ALS-FTLD), further referred to as nonC9orf72 cases. Three healthy controls without neurodegenerative disease were used as negative controls for pTDP-43 pathology. Clinical assessment was performed by an expert neurologist. The diagnosis of ALS was based on the revised El Escorial criteria and the Awaji algorithm [8, 15, 16]. FTLD patients were diagnosed according to published criteria [21, 33]. An experienced pathologist carried out the autopsy. Microscopically, the diagnosis of ALS was assessed by TDP-43 pathology [7, 31]. FTLD-TDP was neuropathologically diagnosed using the Mackenzie criteria [27]. AD and PD pathologies were assessed according to the $\mathrm{Na}$ tional Institute on Aging and Alzheimer's Association (NIA-AA) criteria [23] and the Braak-PD stages [5], respectively. Concomitant $\mathrm{AD}$ or $\mathrm{PD}$ pathology was absent or mild in all cases (NIA-AA degree of AD pathology 0-1 [23]; Braak-PD stage 0-1 [5]) (Additional file 1).

\section{Immunohistochemistry}

Histological examination of the pineal gland and the hypothalamus was performed on 5 - $\mu$ m-thick sections cut from formalin-fixed, paraffin embedded tissue. Primary antibodies 
Table 1 Demographic data and tissue availability by study groups

\begin{tabular}{|c|c|c|c|c|c|c|c|c|c|}
\hline & \multirow{2}{*}{$\begin{array}{l}\text { Male: } \\
\text { female }^{a}\end{array}$} & \multirow{2}{*}{$\begin{array}{l}\text { Mean age } \\
\text { in years } \\
(\mathrm{SD})^{\mathrm{b}}\end{array}$} & \multirow{2}{*}{$\begin{array}{l}\text { Neuro- } \\
\text { pathological } \\
\text { diagnosis }\end{array}$} & \multicolumn{5}{|c|}{ Number of cases available } & \multirow[t]{2}{*}{ Mutations } \\
\hline & & & & $\begin{array}{l}\text { Pineal } \\
\text { gland }\end{array}$ & $\begin{array}{l}\text { Hypo- } \\
\text { thalamus }\end{array}$ & $\begin{array}{l}\text { SCN-related } \\
\text { neurons }\end{array}$ & SON & PVN & \\
\hline \multirow[t]{4}{*}{ C9orf72 cases } & \multirow[t]{4}{*}{$6: 1$} & \multirow[t]{4}{*}{$56.7(4.8)$} & ALS & 4 & 4 & 3 & 3 & 3 & C9orf72 \\
\hline & & & FTLD-TDP & 2 & 2 & 2 & 2 & 2 & C9orf72 \\
\hline & & & ALS-FTLD & 0 & 1 & 1 & 1 & 1 & C9orf72 \\
\hline & & & Total & 6 & 7 & 6 & 6 & 6 & / \\
\hline \multirow[t]{4}{*}{ nonC9orf72 cases } & \multirow[t]{4}{*}{ 13:8 } & \multirow[t]{4}{*}{$62.1(11.2)$} & ALS & 9 & 11 & 2 & 6 & 7 & $\begin{array}{l}10 \text { no mutation, } 1 \\
\text { TARDBP }\end{array}$ \\
\hline & & & FTLD-TDP & 7 & 9 & 2 & 6 & 7 & $\begin{array}{l}5 \text { no mutation, } 1 \text { TUBA4A, } \\
1 \text { GRN, } 1 \text { VCP, } 1 \text { TBK1 }\end{array}$ \\
\hline & & & ALS-FTLD & 1 & 1 & 1 & 1 & 1 & No mutation \\
\hline & & & Total & 17 & 21 & 5 & 13 & 15 & / \\
\hline \multirow[t]{2}{*}{$\begin{array}{l}\text { Healthy control } \\
\text { cases }\end{array}$} & \multirow[t]{2}{*}{$2: 1$} & \multirow[t]{2}{*}{$63.0(2.7)$} & $\begin{array}{l}\text { Healthy } \\
\text { control }\end{array}$ & 3 & 3 & 0 & 0 & 0 & No mutation \\
\hline & & & Total & 3 & 3 & 0 & 0 & 0 & / \\
\hline
\end{tabular}

${ }^{a}$ The sex did not significantly differ between the groups as analyzed by Fisher's exact test (C9orf72 vs. nonC9orf72 cases, $p=0.37$; C9orf72 vs. healthy control cases, $p>0.99$; nonC9orf72 vs. healthy control cases, $p>0.99$ )

b The age did not significantly differ between the three groups as tested by one-way ANOVA $(p=0.43)$

c This column represents the number of cases with hypothalamus sections available that were screened for the presence of SCN-related neurons, SON and PVN

VIP-ir neurons indicates vasoactive intestinal peptide-immunoreactive neurons; SON, supraoptic nucleus; PVN, paraventricular nucleus; SD, standard deviation

used in this study were mouse monoclonal anti-poly(GA) clone 5E9 (MABN889, Merck Millipore, Billerica, USA) at a dilution of $1 / 1000$ for $30 \mathrm{~min}$, rat monoclonal anti-poly(GR) clone 5A2 (MABN778, Merck Millipore) at a dilution of $1 /$ 400 overnight, custom-made rabbit poly(GP) (Thermo Scientific, Waltham, USA) $[19,37]$ at a dilution of $1 / 1000$ for 30 min, custom-made rabbit poly(PR) (Thermo Scientific) [19, 37] at a dilution of $1 / 50$ overnight, mouse monoclonal antipTDP-43 (pS409/410) (TIP-PTD-M01, Cosmo Bio, Tokyo, Japan) or rabbit polyclonal anti-pTDP-43 (pS409/410-2) (TIP-PTD-P02, Cosmo Bio) at a dilution of $1 / 2500$ (double immunostainings) or $1 / 5000$ (single immunostainings) for $30 \mathrm{~min}$, mouse monoclonal anti-synaptophysin ready-to-use 1/1 (IR660, Agilent) for $30 \mathrm{~min}$ and polyclonal rabbit antivasoactive intestinal peptide (VIP) (HPA017324, SigmaAldrich, Saint Louis, MO, USA) at a dilution of $1 / 300$ for 30 min. Stainings for poly(GA), poly(GP), poly(GR), poly(PR) and pTDP-43 were performed as described before [19]. In brief, poly(GP) and pTDP-43 immunostainings were automatically performed by means of the BOND-MAX automated staining system (Leica Biosystems, Wetzlar, Germany) using the Bond Polymer Refine Detection kit (DS9800, Leica Biosystems). Immunohistochemistry for poly(GA) was partially performed in the BOND-MAX automated staining system. Poly(GR) and poly(PR) were performed fully manually. Low $\mathrm{pH}$ heat pretreatment was used for all antibodies except for anti-synaptophysin. For the latter, high $\mathrm{pH}$ heat pretreatment was used. For poly(GA) and poly(GR) immunostaining, an additional pretreatment with formic acid was performed to enhance the signal. Since endogenous brown colored material of the pineal gland tissue interfered with the analysis of small poly(GP), poly(GR), poly(PR) and pTDP-43 inclusions visualized by $3,3^{\prime}$-diaminobenzidine (DAB), these inclusions were also visualized by a Fast Red-type chromogen using the Dako REAL Detection System (K5005, Agilent, Santa Clara, CA, USA) for poly(GR) and poly(PR) or the Bond Polymer Refine Red Detection kit (DS9800, Leica Biosystems) for poly(GP) and pTDP-43. Double immunostainings were performed using the BOND-MAX automated staining system. For the double staining of synaptophysin and DPRs, the pineal gland of three C9orf72 cases and two nonC9orf72 cases was first stained with poly(GA) or poly(GP) visualized by DAB (high $\mathrm{pH}$ pretreatment). Afterwards, synaptophysin immunostaining was visualized by Fast Red. For the double immunostainings of VIP and poly(GA) or pTDP-43, VIP immunostaining was performed first and visualized by $\mathrm{DAB}$ (low $\mathrm{pH}$ pretreatment). Afterwards, a second low $\mathrm{pH}$ heat pretreatment and poly(GA) (with additional formic acid pretreatment) or pTDP-43 immunostaining was performed and visualized by Fast Red.

\section{Microscopic assessment}

The VIP-immunoreactive (ir) neurons evaluated for DPR and PTDP-43 pathology were located in the hypothalamus in between the supraoptic nucleus $(\mathrm{SON})$ and paraventricular nucleus (PVN). This VIP-ir area covers (relay) neurons and efferent projections related to the suprachiasmatic nucleus (SCN) [12]. Consequently, these VIP-ir neurons are presumably involved in sleep/ wake circadian rhythm regulation and were further 
referred to as $\mathrm{SCN}$-related neurons. The pinealocytes and the magnocellular cells of the SON and PVN were neuroanatomically identified by their morphological pattern. The aforementioned brain regions were not available in all cases due to limited sample availability (Table 1, Additional file 1). DPR and pTDP-43 pathologies were assessed by two separate investigators. The assessment of pTDP-43 pathology was performed blinded to the diagnosis and genetics of the patients. DPR pathology was assessed unblinded, since C9orf72 cases show abundant DPR pathology and nonC9orf72 cases do not show DPRs at all. This characteristic staining pattern precludes a blinded evaluation. Evaluation of DPR and pTDP-43 pathology in the pineal gland (C9orf72 $n=6$, nonC9orf72 $n=17$, healthy control $n=$ 3), SON (C9orf72 $\mathrm{n}=6$, nonC9orf72 $n=13$ ) and PVN (C9orf72 $n=6$, nonC9orf72 $n=15$ ) was performed using a semiquantitative grading system, adapted from a previously published grading system [19]. The total amount of pathology was counted in a 40x visual microscopic field with most abundant pathology, considered as the "hotspot area". DPR and pTDP-43 pathology was rated as ' 0 ' if no pathology was present, as ' 1 ' if 1 to 5 pathological lesions were present, as ' 2 ' if 6 to 20 pathological lesions were present, as ' 3 ' if 21 to 50 pathological lesions were present and as ' 4 ' if more than 50 pathological lesions were present in the hotspot area. To evaluate pathology in the SCN-related neurons (C9orf72 $n=6$, nonC9orf72 $n=5$ ), the number of VIP-ir neurons containing poly(GA) or pTDP-43 pathology was divided by the total number of VIP-ir neurons observed in the aforementioned area of the hypothalamus section. Per case, 1 to 13 VIP-ir neurons were observed. The available hypothalamus sections of the healthy control cases did not contain VIP-ir neurons (Table 1). The Leica DM2000 LED microscope (Leica Biosystems) coupled to a Leica DFC $7000 \mathrm{~T}$ camera was used. Images were processed in ImageJ software and combined into figures using CorelDRAW.

\section{Statistical analysis}

Statistical analysis was performed with GraphPad Prism 8.0.1. To compare the age and sex between the groups, a One-way ANOVA test and a Fisher's exact test were used, respectively. Pathological assessments in the C9orf72 and the nonC9orf72 ALS and/or FTLD-TDP cases were compared by a Mann-Whitney test. The significance level was set at $5 \%$.

\section{Results}

\section{Abundant DPR pathology in the pineal gland of C9orf72} cases

The neuropathological diagnosis, sex and age by study groups is shown in Table 1 and a list of the individual cases included in this study is provided in Additional file 1. To investigate the ALS and FTLD-TDP-related pathological changes of the melatonin-producing brain structure, the pineal gland of six C9orf 72 cases and 17 nonC9orf72 cases was analyzed for DPR and pTDP-43 pathology (Table 1-2, Additional file 1). DPR pathology was observed in the pineal gland of all C9orf72 cases $(p<0.0001)$ (Fig. 1a-d, Table 2, Additional file $1)$, more specifically in the melatonin-producing pinealocytes as identified by synaptophysin expression (Fig. 1e). The pineal gland of nonC9orf 72 and healthy control cases was negative for DPR pathology (Table 2, Additional file 1, Additional file 2: Figure S1). The relative abundance of the distinct DPR species in the pineal gland of C9orf72 cases was similar as in other brain regions ( $\operatorname{poly}(\mathrm{GA})>\operatorname{poly}(\mathrm{GP})>\operatorname{poly}(\mathrm{GR})>\operatorname{poly}(\mathrm{PR})$ ), as previously quantified [19] (Table 2, Additional file 1). In all C9orf72, nonC9orf72 and healthy control cases, the pineal gland was virtually free of pTDP-43 pathology (Fig. 1f, Table 2, Additional file 1). As such, no differences in pTDP-43 pathology were observed in the pineal gland sections of C9orf72 cases compared to nonC9orf72 cases.

\section{Poly(GA) inclusions in SCN-related neurons of $\mathrm{C} 9$ orf 72 cases} In order to evaluate neurons associated with the regulation of the circadian sleep/wake cycle, the SCN-related neurons immunostained for VIP in the hypothalamus sections of six C9orf72 cases and five nonC9orf 72 cases were investigated (Fig. 2a, Table 1, Additional file 2: Figure S2). Poly(GA) - the most abundant DPR - and pTDP-43 pathologies were analyzed in this VIP-ir region by means of a double immunostaining using two distinct chromogens (DAB and Fast Red chromogen to visualize VIP and poly(GA)/pTDP-43, respectively). In $50 \%$ of the C9orf72 cases, $9.1-25.0 \%$ of the SCN-related neurons showed poly(GA) pathology (Fig. 2b, Table 2, Additional file 1). In the other half of the C9orf72 cases and in all nonC9orf72 cases, no poly(GA) pathology in SCN-related neurons was observed (Table 2, Additional file 1). Compared to the absence of poly(GA) pathology in the SCN-related neurons of five nonC9orf72 ALS or FTLD cases, the number of poly(GA)-positive SCN-related neurons in $C 9$ orf 72 cases did not reach significance $(p=0.1818)$ (Table 2). Furthermore, in all C9orf72 cases, VIP-negative neurons in the VIP-ir area showed poly(GA) inclusions (Fig. 2b-c). However, VIP-negative neurons in the VIP-ir area were less affected compared to those in the area surrounding the SCN-related neurons and fibers (Fig. 2c). SCN-related neurons were devoid of pTDP-43 inclusions in all analyzed cases (Fig. 2d, Table 2, Additional file 1), indicating that there is no difference in pTDP-43 pathology in SCNrelated neurons between $C$ orf 72 and nonC9orf 72 cases. Due to the absence of pTDP-43 pathology in the VIP-ir neurons, comparison to SCN-related neurons in healthy 
Table 2 Neuropathological analysis of the investigated brain regions

\begin{tabular}{|c|c|c|c|c|c|c|}
\hline \multirow[b]{2}{*}{ Pineal gland } & \multicolumn{2}{|c|}{ C9orf72 ALS and/or FTLD-TDP cases } & \multicolumn{2}{|c|}{ nonC9orf72 ALS and/or FTLD-TDP cases } & \multicolumn{2}{|c|}{ Healthy control cases } \\
\hline & $\begin{array}{l}\text { Number of } \\
\text { positive cases }\end{array}$ & $\begin{array}{l}\text { Median score } \\
\text { (IQR, range) }\end{array}$ & $\begin{array}{l}\text { Number of } \\
\text { positive cases }\end{array}$ & $\begin{array}{l}\text { Median score } \\
\text { (IQR, range) }\end{array}$ & $\begin{array}{l}\text { Number of } \\
\text { positive cases }\end{array}$ & $\begin{array}{l}\text { Median score } \\
\text { (IQR, range) }\end{array}$ \\
\hline Poly(GA) & $\begin{array}{l}6 / 6(100 \%) \\
(p<0.0001)^{a}\end{array}$ & $4(1 ; 2-4)$ & $0 / 17(0 \%)$ & $0(0 ; 0-0)$ & $0 / 3(0 \%)$ & $0(0 ; 0-0)$ \\
\hline Poly(GP) & $\begin{array}{l}3 / 3(100 \%) \\
3 \text { п.а. }\end{array}$ & $4(3 ; 1-4)$ & n.a. ${ }^{d}$ & n.a. ${ }^{d}$ & n.a. ${ }^{d}$ & n.a. ${ }^{d}$ \\
\hline Poly(GR) & $\begin{array}{l}3 / 3(100 \%) \\
3 \text { п.а. }\end{array}$ & $1(1 ; 1-2)$ & n.a. ${ }^{d}$ & n.a. ${ }^{d}$ & n.a. ${ }^{d}$ & n.a. ${ }^{d}$ \\
\hline Poly(PR) & $\begin{array}{l}2 / 3(67 \%) \\
3 \text { n.a. }\end{array}$ & $1(1 ; 0-1)$ & n.a. ${ }^{d}$ & n.a. ${ }^{d}$ & n.a. ${ }^{d}$ & n.a. ${ }^{d}$ \\
\hline pTDP-43 & $0 / 6(100 \%)^{b}$ & $0(0 ; 0-0)$ & 0/17 (0\%) & $0(0 ; 0-0)$ & $0 / 3(0 \%)$ & $0(0 ; 0-0)$ \\
\hline Hypothalamus & $\begin{array}{l}\text { Number of } \\
\text { positive cases }\end{array}$ & $\begin{array}{l}\text { Median score } \\
\text { (IQR, range) }\end{array}$ & $\begin{array}{l}\text { Number of } \\
\text { positive cases }\end{array}$ & $\begin{array}{l}\text { Median score } \\
\text { (IQR, range) }\end{array}$ & $\begin{array}{l}\text { Number of } \\
\text { positive cases }\end{array}$ & $\begin{array}{l}\text { Median score } \\
\text { (IQR, range) }\end{array}$ \\
\hline Poly(GA) & $7 / 7(100 \%)$ & n.a. ${ }^{e}$ & $0 / 21(0 \%)$ & n.a. ${ }^{e}$ & $0 / 3(0 \%)$ & п.а. ${ }^{e}$ \\
\hline pTDP-43 & $4 / 7(57 \%)$ & n.a. ${ }^{e}$ & 15/21 (71\%) & n.a. ${ }^{\mathrm{e}}$ & $0 / 3(0 \%)$ & п.а. ${ }^{\mathrm{e}}$ \\
\hline SCN-related neurons & $\begin{array}{l}\text { Number of } \\
\text { positive cases }\end{array}$ & $\begin{array}{l}\text { Mean \% (SD) VIP-ir } \\
\text { neurons affected }\end{array}$ & $\begin{array}{l}\text { Number of } \\
\text { positive cases }\end{array}$ & $\begin{array}{l}\text { Mean \% (SD) VIP-ir } \\
\text { neurons affected }\end{array}$ & $\begin{array}{l}\text { Number of } \\
\text { positive cases }\end{array}$ & $\begin{array}{l}\text { Mean \% (SD) VIP-ir } \\
\text { neurons affected }\end{array}$ \\
\hline Poly(GA) & $\begin{array}{l}3 / 6(50 \%) \\
(p=0.1818)^{a}\end{array}$ & $8.5(10.6)$ & $0 / 5(0 \%)$ & $0.0(0.0)$ & n.a. & n.a. \\
\hline pTDP-43 & $0 / 6(0 \%)^{b}$ & $0.0(0.0)$ & 0/5 (0\%) & $0.0(0.0)$ & n.a. & n.a. \\
\hline SON magno-cellular cells & $\begin{array}{l}\text { Number of } \\
\text { positive cases }\end{array}$ & $\begin{array}{l}\text { Median score } \\
\text { (IQR, range) }\end{array}$ & $\begin{array}{l}\text { Number of } \\
\text { positive cases }\end{array}$ & $\begin{array}{l}\text { Median score } \\
\text { (IQR, range) }\end{array}$ & $\begin{array}{l}\text { Number of } \\
\text { positive cases }\end{array}$ & $\begin{array}{l}\text { Median score } \\
\text { (IQR, range) }\end{array}$ \\
\hline Poly(GA) & $0 / 6(0 \%)^{b}$ & $0(0 ; 0-0)$ & $0 / 13(0 \%)$ & $0(0 ; 0-0)$ & n.a. & n.a. \\
\hline pTDP-43 & $0 / 6(0 \%)^{b}$ & $0(0 ; 0-0)$ & 0/13 (0\%) & $0(0 ; 0-0)$ & n.a. & n.a. \\
\hline $\begin{array}{l}\text { PVN } \\
\text { magnocellular cells }\end{array}$ & $\begin{array}{l}\text { Number of } \\
\text { positive cases }\end{array}$ & $\begin{array}{l}\text { Median score } \\
\text { (IQR, range) }\end{array}$ & $\begin{array}{l}\text { Number of } \\
\text { positive cases }\end{array}$ & $\begin{array}{l}\text { Median score } \\
\text { (IQR, range) }\end{array}$ & $\begin{array}{l}\text { Number of } \\
\text { positive cases }\end{array}$ & $\begin{array}{l}\text { Median score } \\
\text { (IQR, range) }\end{array}$ \\
\hline Poly(GA) & $0 / 6(0 \%)^{b}$ & $0(0 ; 0-0)$ & 0/15 (0\%) & $0(0 ; 0-0)$ & n.a. & n.a. \\
\hline pTDP-43 & $0 / 6(0 \%)^{b}$ & $0(0 ; 0-0)$ & $0 / 15(0 \%)$ & $0(0 ; 0-0)$ & n.a. & n.a. \\
\hline
\end{tabular}

${ }^{a} p$-values of Mann-Whitney test are shown for comparison of poly(GA) pathology between the C9orf72 and the nonC9orf72 ALS and/or FTLD-TDP cases as a reference

${ }^{\mathrm{b}}$ No statistical analysis was performed for pTDP-43 pathology, since the pineal gland and SCN-related neurons of C9orf72 and nonC9orf72 cases do not show any pTDP-43 pathology. We neither performed statistical analysis for pathological assessments in the SON and PVN, since all cases were negative for poly(GA) and PTDP-43 pathology in the magnocellular cells of these brain nuclei

' Three out of the six C9orf72 ALS and/or FTLD-TDP cases were not assessed for poly(GP), poly(GR) and poly(PR) pathology since prolonged fixation times of the pineal gland masked the detection of the aforementioned DPR inclusions

${ }^{d}$ Pineal gland tissue of the nonC9orf72 ALS and/or FTLD-TDP and healthy control cases was only stained for the most abundant DPR (poly(GA)) to confirm the cases did not carry the C9orf72 repeat expansion

${ }^{\mathrm{e}}$ The general pathology in the hypothalamus was not semiquantitatively assessed

n.a. indicates not available; SCN, suprachiasmatic nucleus; SON, supraoptic nucleus; PVN, paraventricular nucleus; IQR, interquartile range; SD, standard deviation

control cases negative for pTDP-43 pathology was not necessary. In two of the six C9orf 72 cases and two of the five nonC9orf72 cases, VIP-negative neurons in between the SCN-related neurons were affected by pTDP-43 pathological lesions (Fig. 2d).

\section{No neuropathological changes in the neuroendocrine magnocellular cells of the PVN and SON}

To compare the vulnerability of the pinealocytes to abnormal protein aggregation with other neuroendocrine brain structures, the magnocellular cells of the SON and PVN, producing vasopressin and oxytocin, were analyzed for neuropathological changes (Table 1-2, Additional file 1). These neuroendocrine neurons contained neither poly(GA) nor pTDP-43 pathology (Fig. 3a-f, Table 2, Additional file 1). However, poly(GA) inclusions and pTDP- 43 pathology were observed in the smaller neurons in between the magnocellular cells of the PVN (Fig. 3d,f).

\section{Discussion}

Neuropathological assessments of brain regions associated with the circadian sleep/wake cycle are lacking in 


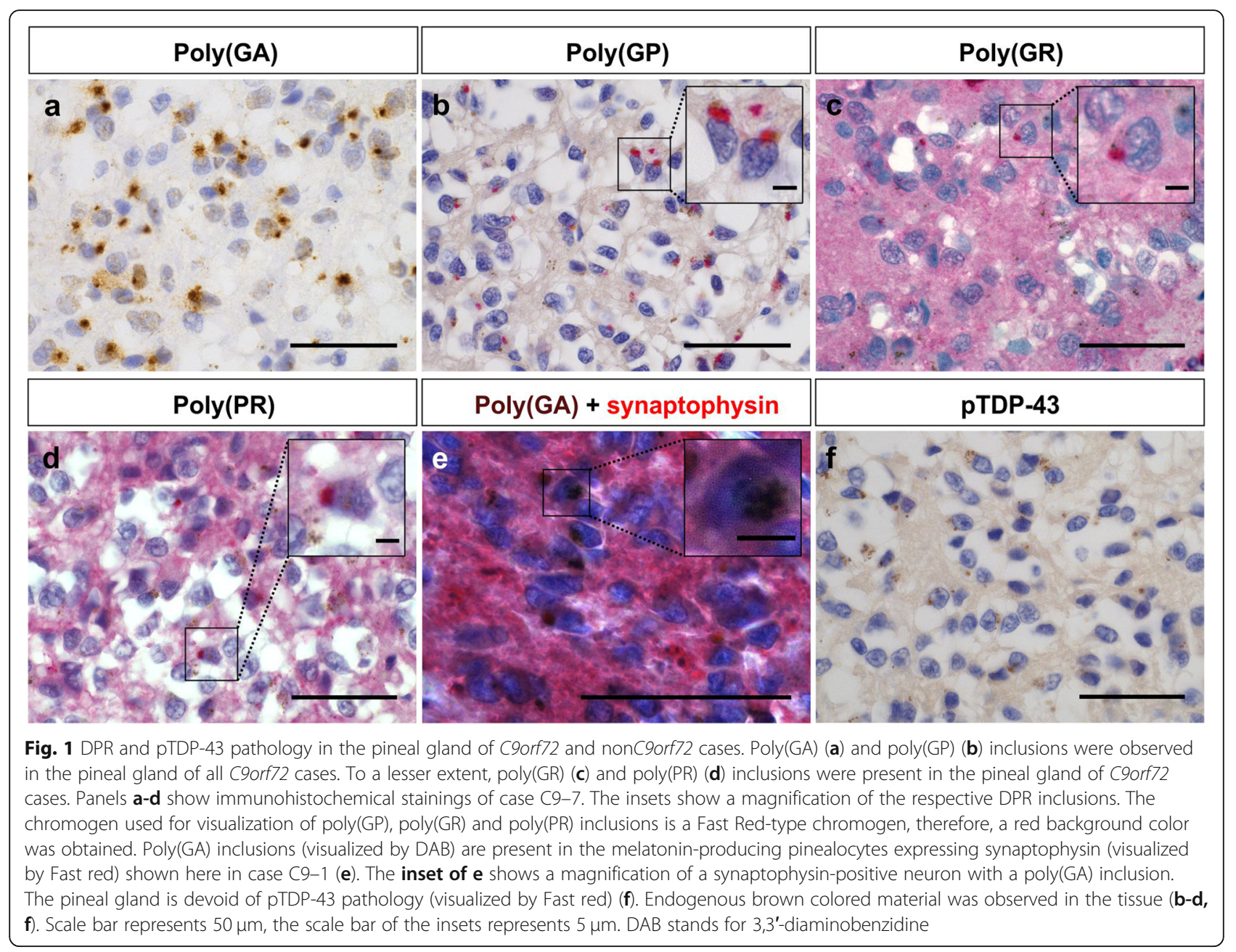

patients with ALS and/or FTLD. We now conducted a neuropathological study of the pineal gland and VIP-ir SCN-related neurons in C9orf72- and nonC9orf72-related ALS and/or FTLD-TDP patients. In C9orf72 cases, we observed numerous DPR pathological lesions in the melatonin-producing pinealocytes. On the other hand, pTDP-43 pathology was absent in the pineal gland of both C9orf72 and nonC9orf72 cases. Although not statistically significant towards nonC9orf 72 cases, the VIP-ir SCN-related neurons showed few poly(GA) inclusions in $50 \%$ of the C9orf72 cases. No pTDP-43 pathology was observed in the SCN-related neurons of both C9orf72 and nonC9orf72 cases. Besides, VIP-negative neurons present in the VIP-ir area showed DPR and/or pTDP-43 pathology. The abundant DPR pathology seemed to be specific to the neuroendocrine pineal gland, since other neuroendocrine brain structures (the magnocellular cells of SON and PVN) in the hypothalamus were unaffected. These magnocellular neuroendocrine hypothalamic nuclei were also spared from pTDP-43 pathology, confirming previously published data [11].
In previous studies, $\mathrm{AD}$ - and $\mathrm{PD}$-related pathological lesions were mainly observed in the SCN rather than in the pineal gland $[17,32,36]$. This neuroanatomically differs compared to C9orf72 cases, in which pinealocytes are housing a significant number of pathological DPR inclusions, whereas the SCN-related neurons are only affected in $50 \%$ of the C9orf 72 cases. Consequently, in C9orf72 cases, mainly the executor, and to a lesser extent neurons related to the "central biological clock", are affected by DPR pathology. Whether this explains why ALS patients show more subtle sleep abnormalities and do not display the same prominent circadian sleep/wake disturbances as $\mathrm{AD}$ and $\mathrm{PD}$ patients, remains to be investigated.

It has previously been shown that the DPR regional burden in post-mortem brain tissue did not correlate with neurodegeneration, while the neuroanatomical distribution of pTDP-43 pathology did [14, 26]. Nevertheless, DPRs were specifically present in pinealocytes as a neuroendocrine cell type and previously published findings show cellular dysfunction as a major outcome of DPR toxicity in many 

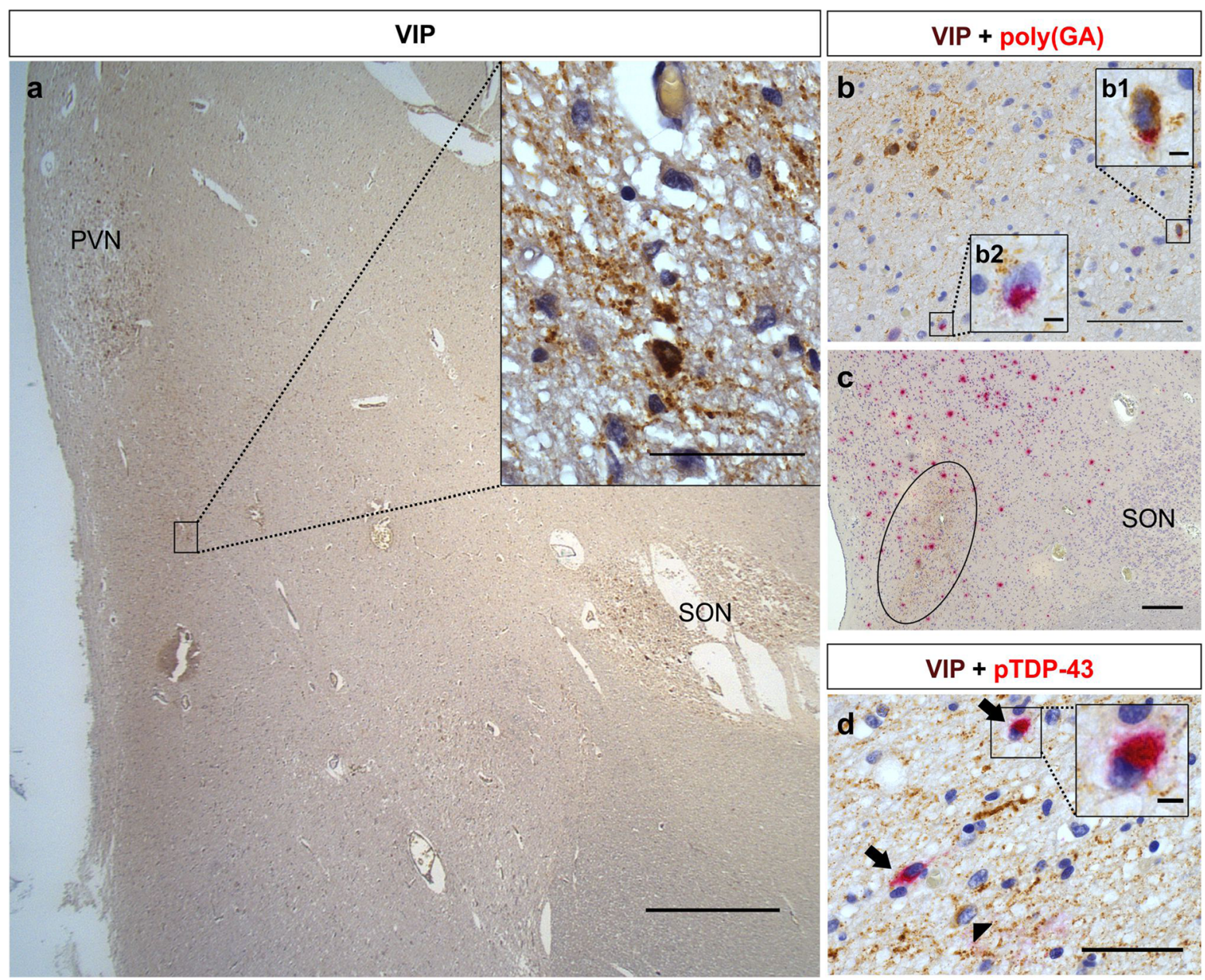

Fig. 2 Neuropathological investigation of the SCN-related neurons in the hypothalamus of C9orf72 and nonC9orf72 cases. VIP-ir neurons in the hypothalamus at the level of the SON and PVN were referred to as SCN-related neurons (case nonC9-16) (a). The inset shows VIP-

immunostaining in neurons and fibers (a). Poly(GA) pathology (visualized by Fast red) was observed in few VIP-ir SCN-related neurons (visualized in brown with DAB) in half of the C9orf72 cases (case C9-3) (b). Inset b1 shows a magnification of a SCN-related neuron with poly(GA) pathology; inset b2 shows a magnification of a VIP-negative neuron with a poly(GA) inclusion. Poly(GA) inclusions (visualized by Fast red) were observed in the area of the SCN-related neurons and fibers (encircled) visualized in brown by DAB (c), however, more poly(GA) inclusions are observed in the area surrounding the SCN-related neurons and fibers (case C9-1) (c). SCN-related neurons were usually spared from pTDP-43 pathology. In some cases, pTDP-43 pathology (black arrows) (visualized by Fast red) was observed in VIP-negative neurons located in between the SCN-related neurons (arrowhead) and fibers (case nonC9-1) (d). The inset in $\mathbf{d}$ shows a magnification of a VIP-negative neuron with pTDP-43 pathology. Scale bars represent $1000 \mu \mathrm{m}$ in $\mathbf{a}, 100 \mu \mathrm{m}$ in $\mathbf{b}, 200 \mu \mathrm{m}$ in c, $50 \mu \mathrm{m}$ in $\mathbf{d}$ and inset of $\mathbf{a}$, and $5 \mu \mathrm{m}$ in insets of $\mathbf{b}$ and d. VIP-ir stands for vasoactive intestinal peptide-immunoreactive; SCN, suprachiasmatic nucleus; DAB, 3,3'-diaminobenzidine

in vitro and in vivo models [4]. Therefore, we hypothesize that DPR pathology in the pinealocytes might lead to pinealocyte dysfunction, and mild DPR pathology in the SCNrelated neurons could implicate disturbances along the melatonin-stimulating pathway. This hypothesis needs to be tested by comparing sleep disturbances among ALS and/or FTLD patients with and without the C9orf72 repeat expansion. Moreover, it remains to be investigated whether DPR pathology may directly impair the melatonin-synthesizing and -secreting function of the pinealocytes. This could be done by e.g. determining serum and cerebrospinal fluid melatonin levels of ALS and/or FTLD patients with and without the C9orf72 repeat expansion. Nonetheless, the morphological differences between the distinct neuroendocrine brain cells (pinealocytes versus magnocellular cells of SON and PVN) could also explain the specific appearance of DPR pathology in the pinealocytes, representing a harmless accumulation of these proteins rather than a functional alteration of the sleep/wake-associated cells. This explanation is in line with the abundant DPR pathology in cerebellar granule cells, without accompanying pTDP-43 inclusions and neurodegeneration [26].

Of note, DPR pathology does not exclusively affect neurons and has been shown before in the Sertoli cells 


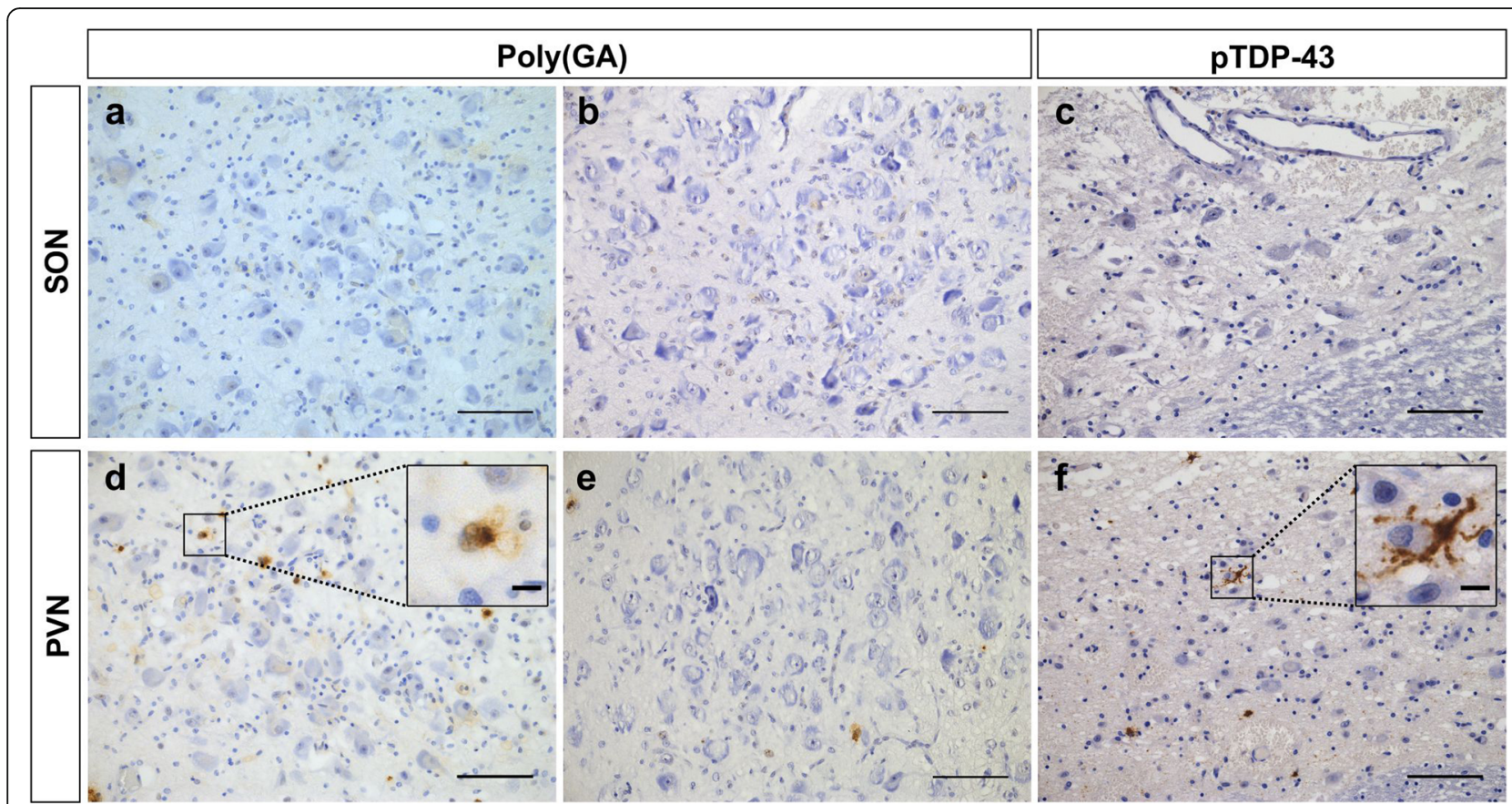

Fig. 3 Microscopic assessment of the neuroendocrine magnocellular cells of the SON and PVN in the hypothalamus. The magnocellular cells of the SON (a-c) and PVN (d-f) were spared from poly(GA) pathology in C9orf72 cases (case C9-5 and C9-2) (a-b, $\mathbf{d}-\mathbf{e})$ and devoid of pTDP-43 pathology in C9orf72 and nonC9orf72 cases (case nonC9-21) (c,f). However, pathological lesions appeared in the smaller neurons in between the magnocellular neurons ( $\mathbf{d}-\mathbf{f}$ ). The insets in $\mathbf{d}$ and $\mathbf{f}$ show a magnification of smaller neurons with poly(GA) and pTDP-43 pathology, respectively. Scale bars represent $100 \mu \mathrm{m}$ in a-f and $10 \mu \mathrm{m}$ in the insets of $\mathbf{d}$ and $\mathbf{f}$. SON stands for supraoptic nucleus; PVN, paraventricular nucleus

[3], ependymal cells [35] and, more recently, in the skeletal muscle [10] of C9orf72 patients. Pinealocytes are considered as a neuroendocrine cell type, without being real neurons. Therefore, the abundant DPR pathology in pinealocytes expands the non-neuronal spectrum of DPR pathology.

There are several limitations of our study. First, the cohort size in this study is small (especially for cases analyzed for the SCN-related neurons) as tissue availability was limited. The low number of cases could explain the lack of significance when comparing poly(GA) pathology in the SCN-related neurons of the C9orf72 cases to the nonC9orf72 cases. However, the complete absence of DPRs in nonC9orf72 cases and the significant prevalence of DPRs in other brain regions of C9orf72 cases, such as the pineal gland, argues in favor of C9orf72-related DPR expression in the SCN-related neurons. Second, pre-existing paraffin blocks of the hypothalamus were available covering only parts of this brain region. Therefore, the tissue was not suitable for stereological assessments. Consequently, we could not assess neuron loss in the investigated brain regions to observe a direct effect of DPR aggregates on neuronal viability. Third, clinical data on sleep disturbances were not collected for our patients and, therefore, we could not investigate the correlation between the neuropathological findings and clinical assessments of circadian sleep/wake disturbances. Finally, breathing abnormalities and muscle weakness will most likely still have the largest share in explaining sleep abnormalities of C9orf72 ALS patients.

\section{Conclusions}

We observed DPR, but no pTDP-43 pathology in the circadian sleep/wake-associated cells of ALS and/or FTLD-TDP patients. Abundant DPR pathological lesions in the pineal gland of C9orf72 ALS and/or FTLD-TDP cases may indicate the involvement of pinealocyte dysfunction. Few poly(GA) inclusions observed in VIP-ir SCN-related neurons could implicate disturbances of the SCN-pineal gland axis in C9orf72 cases. These neuropathological findings provide new insights in an underlying pathological correlative for the circadian sleep/wake disturbances, which might be involved in the disease course of ALS and/or FTLDTDP patients carrying the C9orf72 hexanucleotide repeat expansion. Further investigation on the circadian melatonin-producing and -secreting capacity of the pinealocytes, and the presence of circadian sleep/wake disturbances in C9orf72 ALS and/or FTLD-TDP patients, is needed to clarify the functional impact of the DPR pathology in circadian sleep/wake-associated cells. 


\section{Supplementary information}

Supplementary information accompanies this paper at https://doi.org/10. 1186/s40478-019-0845-9.

Additional file 1: List of human autopsy cases and neuropathological assessments per case

Additional file 2: Figure S1. Poly (GA) pathology in the pineal gland of C9orf72 and nonC9orf72 ALS and FTLD cases. Figure S2. VIPimmunostaining of the SCN-related neurons in C9orf72 and nonC9orf72 ALS and FTLD cases.

\section{Abbreviations}

AD: Alzheimer's disease; ALS: Amyotrophic lateral sclerosis; C9orf72: Chromosome 9 open reading frame 72; DAB: 3,3'-diaminobenzidine; DPR: Dipeptide repeat protein; FLTD-TDP: Frontotemporal lobar degeneration with TDP-43 pathology; FTD: Frontotemporal dementia; IQR: Interquartile range; Ir: Immunoreactive; NIA-AA: National Institute on Aging and Alzheimer's Association; PD: Parkinson's disease; pTDP43: Phosphorylated transactive response DNA-binding protein $43 \mathrm{kDa}$; PVN: Paraventricular nucleus; RBD: Rapid eye movement sleep behavior disorder; SCN: Suprachiasmatic nucleus; SD : Standard deviation; SON: Supraoptic nucleus; VIP: Vasoactive intestinal peptide

\section{Acknowledgements}

We thank Alicja Ronisz, Simona Ospitalieri and Petra Weckx for technical support.

\section{Authors' contributions}

LD: study design, immunohistochemistry, microscopic assessments, neuropathology, data analysis, manuscript drafting and preparation. EVS: microscopic assessments (blinded investigator), critical review of the manuscript. RV: clinical neurology, critical review of the manuscript. PVD: study design, clinical neurology, study management, manuscript preparation. KP: study design, study management, manuscript preparation. DRT: study design, neuropathology, data analysis, study management, manuscript preparation. All authors read and approved the final manuscript.

\section{Funding}

LD is funded by a PhD Fellowship of the Research Foundation - Flanders (FWO-Vlaanderen) (1165119 N). EVS is funded by an SB PhD Fellowship of FWO-Vlaanderen (1S46219N). PVD holds a senior clinical investigatorship of FWO-Vlaanderen and is supported by the ALS Liga Belgium and the KU Leuven ALS funds 'Een hart voor ALS', 'Laeversfonds voor ALS onderzoek' and Valéry Perrier Race against ALS Fund'. PVD and DRT received C1-internal funds from KU Leuven (C14-17-107). DRT and RV received funding from FWO-Odysseus grant No. G0F8516N and Vlaamse Impulsfinanciering voor Netwerken voor Dementie Onderzoek (VIND, IWT 135043). RV was additionally funded by Mady Browaeys Fund for Research into Frontotemporal degeneration

\section{Availability of data and materials}

Most data generated or analyzed during this study are included in this published article and in its supplementary information files. Additional data analyzed during the current study are available from the corresponding author upon reasonable request.

\section{Ethics approval and consent to participate}

All human brain tissue was provided by the UZ Leuven brain biobank (Belgium) and the municipal hospital Offenbach (Germany) in accordance with the Belgian and German law and approved by local ethical committees. Ethical approval for the use of tissue from these cases for this study was granted by the UZ/KU-Leuven ethical committee (Belgium) (S60803).

\section{Consent for publication}

Not applicable for this study, which did not use person's data. Only anonymized or pseudonymized data were processed.

\section{Competing interests}

RV's institution has a clinical trial agreement (RV as PI) with AbbVie (USA) Biogen (USA), Genentech (USA), Novartis (Switzerland), and Roche (Switzerland). PVD participated in advisory board meetings for Genzyme (USA), Pfizer (USA), Biogen (USA), Cytokinetics (USA), Mitsubishi Tanabe (Japan), CSL Behring (USA), Alexion Pharmaceuticals (USA). DRT received speaker honorary from Novartis Pharma AG (Switzerland), travel reimbursement from GE-Healthcare (UK) and UCB (BE), and collaborated with Novartis Pharma AG (Switzerland), Probiodrug (Germany), GE-Healthcare (UK), and Janssen Pharmaceutical Companies (Belgium).

\section{Author details}

'Department of Neurosciences, Laboratory for Molecular Neurobiomarker Research, KU Leuven (University of Leuven), Leuven Brain Institute (LBI), Leuven, Belgium. ${ }^{2}$ Department of Imaging and Pathology, Laboratory for Neuropathology, KU Leuven (University of Leuven), Leuven Brain Institute (LBI), Leuven, Belgium. ${ }^{3}$ Laboratory Medicine, University Hospitals Leuven, Leuven, Belgium. ${ }^{4}$ Department of Neurosciences, Laboratory for Neurobiology, KU Leuven (University of Leuven) and Center for Brain \& Disease Research, VIB, Leuven Brain Institute (LBI), Leuven, Belgium.

${ }^{5}$ Department of Neurology, University Hospitals Leuven, Leuven, Belgium. ${ }^{6}$ Department of Neurosciences, Laboratory for Cognitive Neurology, KU

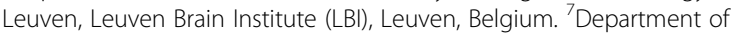
Pathology, University Hospitals Leuven, Leuven, Belgium.

Received: 3 October 2019 Accepted: 11 November 2019

Published online: 02 December 2019

\section{References}

1. Ahmed RM, Newcombe REA, Piper AJ, Lewis SJ, Yee BJ, Kiernan MC, Grunstein RR (2016) Sleep disorders and respiratory function in amyotrophic lateral sclerosis. Sleep Med Rev 26:33-42. https://doi.org/10.1016/.jsmrv.2015.05.007

2. Anderson KN, Hatfield C, Kipps C, Hastings M, Hodges JR (2009) Disrupted sleep and circadian patterns in frontotemporal dementia. Eur J Neurol 16: 317-323. https://doi.org/10.1111/j.1468-1331.2008.02414x

3. Ash PEA, Bieniek KF, Gendron TF, Caulfield T, Lin W-L, DeJesus-Hernandez M, Van Blitterswijk MM, Jansen-West K, Paul JW III, Rademakers R, Boylan KB, Dickson DW, Petrucelli L (2013) Unconventional translation of C9ORF72 GGGGCC expansion generates insoluble polypeptides specific to C9FTD/ALS. Neuron 77:639-646. https://doi.org/10.1016/j.neuron.2013.02.004

4. Balendra R, Isaacs AM (2018) C9orf72-mediated ALS and FTD: multiple pathways to disease. Nat Rev Neurol 14:544-558. https://doi.org/10.1038/ s41582-018-0047-2

5. Braak H, Del Tredici K, Rüb U, de Vos RAl, Jansen Steur ENH, Braak E (2003) Staging of brain pathology related to sporadic Parkinson's disease. Neurobiol Aging 24:197-211. https://doi.org/10.1016/S0197-4580(02)00065-9

6. Breen DP, Vuono R, Nawarathna U, Fisher K, Shneerson JM, Reddy AB, Barker RA (2014) Sleep and circadian rhythm regulation in early parkinson disease. JAMA Neurol 71:589-595. https://doi.org/10.1001/jamaneurol.2014.65

7. Brettschneider J, Del Tredici K, Toledo JB, Robinson JL, Irwin DJ, Grossman M, Suh E, Van Deerlin VM, Wood EM, Baek Y, Kwong L, Lee EB, Elman L, Mccluskey L, Fang L, Feldengut S, Ludolph AC, Lee VM, Braak H, Trojanowski JQ (2013) Stages of pTDP-43 pathology in amyotrophic lateral sclerosis. Ann Neurol 74:20-38. https://doi.org/10.1002/ana.23937

8. Brooks BR, Miller RG, Swash M, Munsat TL, For the World Federation of Neurology Research Group on Motor Neuron Diseases (2000) El Escorial revisited : revised criteria for the diagnosis of amyotrophic lateral sclerosis. Amyotroph Lateral Scler Other Motor Neuron Disord 1:293-299. https://doi. org/10.1080/146608200300079536

9. Congiu P, Mariani S, Milioli G, Parrino L, Tamburrino L, Borghero G, Defazio G, Pereira B, Fantini M, Puligheddu M (2019) Sleep cardiac dysautonomia and EEG oscillations in amyotrophic lateral sclerosis. Sleep 42. https://doi. org/10.1093/sleep/zsz164

10. Cykowski MD, Dickson DW, Powell SZ, Arumanayagam AS, Rivera AL, Appel SH (2019) Dipeptide repeat (DPR) pathology in the skeletal muscle of ALS patients with C9ORF72 repeat expansion. Acta Neuropathol 138:667-670. https://doi.org/10.1007/s00401-019-02050-8

11. Cykowski MD, Takei H, Schulz PE, Appel SH, Powell SZ (2014) TDP-43 pathology in the basal forebrain and hypothalamus of patients with amyotrophic lateral sclerosis. Acta Neuropathol Commun 2:171. https://doi. org/10.1186/s40478-014-0171-1 
12. Dai J, Swaab DF, Buijs RM (1997) Distribution of vasopressin and vasoactive intestinal polypeptide (MP) fibers in the human hypothalamus with special emphasis on suprachiasmatic nucleus efferent projections. J Comp Neurol 383:397-414. https:/ doi.org/10.1002/(sici)1096-9861(19970714)383:4<397:aid-cne1>3.0.co;2-y

13. Daoud H, Postuma RB, Bourassa CV, Rochefort D, Gauthier MT, Montplaisir J, Gagnon J, Arnulf I, Dauvilliers Y, Charley CM, Inoue Y, Sasai T, Högl B, Desautels A, Frauscher B, Cochen De Cock V, Rouleau GA, Dion PA (2014) C9orf72 repeat expansions in rapid eye movement sleep behaviour disorder. Can J Neurol Sci 41:759-762. https://doi.org/10.1017/cjn.2014.39

14. Davidson Y, Robinson AC, Liu X, Wu D, Troakes C, Rollinson S, MasudaSuzukake M, Suzuki G, Nonaka T, Shi J, Tian J, Hamdalla H, Ealing J, Richardson A, Jones M, Pickering-Brown S, Snowden JS, Hasegawa M, Mann DMA (2016) Neurodegeneration in frontotemporal lobar degeneration and motor neurone disease associated with expansions in C9orf72 is linked to TDP-43 pathology and not associated with aggregated forms of dipeptide repeat proteins. Neuropathol Appl Neurobiol 42:242-254. https:/doi.org/10.1111/nan.12292

15. de Carvalho M, Dengler R, Eisen A, England JD, Kaji R, Kimura J, Mills K, Mitsumoto H, Nodera H, Shefner J, Swash M (2008) Electrodiagnostic criteria for diagnosis of ALS. Clin Neurophysiol 119:497-503. https://doi.org/10. 1016/j.clinph.2007.09.143

16. de Carvalho M, Swash M (2009) Awaji diagnostic algorithm increases sensitivity of El Escorial criteria for ALS diagnosis. Amyotroph Lateral Scler 10:53-57. https://doi.org/10.1080/17482960802521126

17. De Pablo-Fernández E, Courtney R, Warner TT, Holton JL (2018) A histologic study of the circadian system in Parkinson disease, multiple system atrophy, and progressive Supranuclear palsy. JAMA Neurol 75:1008-1012. https://doi. org/10.1001/jamaneurol.2018.0640

18. Debray S, Race V, Crabbé V, Herdewyn S, Matthijs G, Goris A, Dubois B, Thijs V, Robberecht W, Van Damme P (2013) Frequency of C9orf72 repeat expansions in amyotrophic lateral sclerosis: a belgian cohort study. Neurobiol aging 34:2890.e7-2890.e12. https://doi.org/10.1016/j. neurobiolaging.2013.06.009

19. Dedeene L, Van Schoor E, Race V, Moisse M, Vandenberghe R, Poesen K, Van Damme P, Thal DR (2019) An ALS case with 38 (G4C2)-repeats in the C9orf72 gene shows TDP-43 and sparse dipeptide repeat protein pathology. Acta Neuropathol 137:855-858. https://doi.org/10.1007/s00401-019-01996-z

20. Diaz-Abad M, Buczyner J, Venza B, Scharf S, Kwan J, Lubinski B, Russell J (2018) Poor sleep quality in patients with amyotrophic lateral sclerosis at the time of diagnosis. J Clin Neuromuscul Dis 20:60-68. https://doi.org/10. 1097/CND.0000000000000234

21. Gorno-Tempini ML, Hillis AE, Weintraub S, Kertesz A, Mendez M, Cappa SF, Ogar JM, Rohrer JD, Black S, Boeve BF, Manes F, Dronkers NF, Vandenberghe R, Rascovsky K, Patterson K, Miller BL, Knopman DS, Hodges $J R$, Mesulam MM, Grossman M (2011) Classification of primary progressive aphasia and its variants. Neurology 76:1006-1014. https://doi.org/10.1212/ WNL.0b013e31821103e6

22. Huang Z, Liu Q, Peng Y, Dai J, Xie Y, Chen W, Long S, Pei Z, Su H, Yao X (2018) Circadian rhythm dysfunction accelerates disease progression in a mouse model with amyotrophic lateral sclerosis. Front Neurol 9:218. https:// doi.org/10.3389/fneur.2018.00218

23. Hyman BT, Phelps CH, Beach TG, Bigio EH, Cairns NJ, Carrillo MC, Dickson DW, Duyckaerts C, Frosch MP, Masliah E, Mirra SS, Nelson PT, Schneider JA, Thal DR, Thies B, Trojanowski JQ, Vinters HV, Montine TJ (2012) National Institute on Aging - Alzheimer's association guidelines for the neuropathologic assessment of Alzheimer's disease. Alzheimers Dement 8: 1-13. https://doi.org/10.1016/j.jalz.2011.10.007

24. Liu S, Huang Y, Tai H, Zhang K, Wang Z, Shen D, Fu H, Su N, Shi J, Ding Q, Liu M, Guan Y, Gao J, Cui L (2018) Excessive daytime sleepiness in Chinese patients with sporadic amyotrophic lateral sclerosis and its association with cognitive and behavioural impairments. J Neurol Neurosurg Psychiatry 89: 1038-1043. https://doi.org/10.1136/jnnp-2018-318810

25. Lo Coco D, Mattaliano P, Spataro R, Mattaliano A, La Bella V (2011) Sleep wake disturbances in patients with amyotrophic lateral sclerosis. J Neurol Neurosurg Psychiatry 82:839-842. https://doi.org/10.1136/jnnp.2010.228007

26. Mackenzie IRA, Frick P, Grässer FA, Gendron TF, Petrucelli L, Cashman NR, Edbauer D, Kremmer E, Prudlo J, Troost D, Neumann M (2015) Quantitative analysis and clinico-pathological correlations of different dipeptide repeat protein pathologies in C9ORF72 mutation carriers. Acta Neuropathol 130: 845-861. https://doi.org/10.1007/s00401-015-1476-2

27. Mackenzie IRA, Neumann M, Bigio EH, Cairns NJ, Alafuzoff I, Kril J, Kovacs GG, Ghetti B, Halliday G, Holm IE, Ince PG, Kamphorst W, Revesz T,
Rozemuller AJM, Kumar-Singh S, Akiyama H, Baborie A, Spina S, Dickson DW, Trojanowski JQ, Mann DMA (2009) Nomenclature for neuropathologic subtypes of frontotemporal lobar degeneration: consensus recommendations. Acta Neuropathol 117:15-18. https://doi.org/10.1007/ s00401-008-0460-5

28. McCarter SJ, St. Louis EK, Boeve BF (2016) Sleep Disturbances in Frontotemporal Dementia. Curr Neurol Neurosci Rep 16:85. https://doi.org/ 10.1007/s11910-016-0680-3

29. Mok K, Traynor BJ, Schymick J, Tienari PJ, Laaksovirta H, Peuralinna T, Myllykangas L, Chiò A, Shatunov A, Boeve BF, Boxer AL, DeJesus-Hernandez M, Mackenzie IR, Waite A, Williams N, Morris HR, Simón-Sánchez J, van Swieten JC, Heutink P, Restagno G, Mora G, Morrison KE, Shaw PJ, Rollinson PS, Al-Chalabi A, Rademakers R, Pickering-Brown S, Orrell RW, Nalls MA, Hardy J (2012) The chromosome 9 ALS and FTD locus is probably derived from a single founder. Neurobiol Aging 33(209):e3-209.e8. https:/doi.org/ 10.1016/j.neurobiolaging.2011.08.005

30. Mori K, Weng S-M, Arzberger T, May S, Rentzsch K, Kremmer E, Schmid B, Kretzschmar HA, Cruts M, Van Broeckhoven C, Haass C, Edbauer D (2013) The C9orf72 GGGGCC repeat is translated into aggregating dipeptide-repeat proteins in FTLD/ALS. Science 339:1335-1338. https://doi.org/10.1126/ science. 1232927

31. Neumann M, Sampathu DM, Kwong LK, Truax AC, Micsenyi MC, Chou TT, Bruce J, Schuck T, Grossman M, Clark CM, McCluskey LF, Miller BL, Masliah E, Mackenzie IR, Feldman H, Feiden W, Kretzschmar HA, Trojanowski JQ, Lee VM-Y (2006) Ubiquitinated TDP-43 in Frontotemporal lobar degeneration and amyotrophic lateral sclerosis. Science 314:130-133. https://doi.org/10, 1126/science.1134108

32. Pardo CA, Martin $\sqcup$, Troncoso JC, Price DL (1990) The human pineal gland in aging and Alzheimer's disease: patterns of cytoskeletal antigen immunoreactivity. Acta Neuropathol 80:535-540. https://doi.org/10.1007/bf00294615

33. Rascovsky K, Hodges JR, Knopman D, Mendez MF, Kramer JH, Neuhaus J, van Swieten JC, Seelaar H, Dopper EGP, Onyike CU, Hillis AE, Josephs K, Boeve B, Kertesz A, Seeley W, Rankin K, Johnson J, Gorno-Tempini M, Rosen H, Prioleau-Latham C, Lee A, Kipps C, Lillo P, Piguet O, Rohrer J, Rossor M, Warren J, Fox N, Galasko D, Salmon D, Black S, Mesulam M, Weintraub S, Dickerson B, Diehl-Schmid J, Pasquier F, Deramecourt V, Lebert F, Pijnenburg Y, Chow T, Manes F, Grafman J, Cappa S, Freedman M, Grossman M, Miller B (2011) Sensitivity of revised diagnostic criteria for the behavioural variant of frontotemporal dementia. Brain 134:2456-2477. https://doi.org/10.1093/brain/awr179

34. Renton AE, Chiò A, Traynor BJ (2014) State of play in amyotrophic lateral sclerosis genetics. Nat Neurosci 17:17-23. https://doi.org/10.1038/nn.3584

35. Schludi MH, May S, Grässer FA, Rentzsch K, Kremmer E, Küpper C, Klopstock $\mathrm{T}$, German Consortium for Frontotemporal Lobar Degeneration, Bavarian Brain Banking Alliance, Arzberger T, Edbauer D (2015) Distribution of dipeptide repeat proteins in cellular models and C9orf72 mutation cases suggests link to transcriptional silencing. Acta Neuropathol 130:537-555. https://doi.org/10.1007/s00401-015-1450-z

36. Stopa EG, Volicer L, Kuo-Leblanc V, Harper D, Lathi D, Tate B, Satlin A (1999) Pathologic evaluation of the human suprachiasmatic nucleus in severe dementia. J Neuropathol Exp Neurol 58:29-39. https://doi.org/10.1097/ 00005072-199901000-00004

37. Swinnen B, Bento-Abreu A, Gendron TF, Boeynaems S, Bogaert E, Nuyts R, Timmers M, Scheveneels W, Hersmus N, Wang J, Mizielinska S, Isaacs AM, Petrucelli L, Lemmens R, Van Damme P, Van Den Bosch L, Robberecht W (2018) A zebrafish model for C9orf72 ALS reveals RNA toxicity as a pathogenic mechanism. Acta Neuropathol 135:427-443. https://doi.org/10. 1007/s00401-017-1796-5

38. Videnovic A, Noble C, Reid KJ, Peng J, Turek FW, Marconi A, Rademaker AW, Simuni T, Zadikoff C, Zee PC (2014) Circadian melatonin rhythm and excessive daytime sleepiness in Parkinson disease. JAMA Neurol 71:463-469. https://doi.org/10.1001/jamaneurol.2013.6239

39. Vrijsen B, Buyse B, Belge C, Robberecht W, Van Damme P, Decramer M, Testelmans D (2015) Noninvasive ventilation improves sleep in amyotrophic lateral sclerosis: a prospective Polysomnographic study. J Clin Sleep Med 11: 559-566. https://doi.org/10.5664/jcsm.4704

40. Wu Y-H, Swaab DF (2005) The human pineal gland and melatonin in aging and Alzheimer's disease. J Pineal Res 38:145-152. https://doi.org/10.1111/j. 1600-079X.2004.00196.x

41. Zhang T, Jiang $X$, Xu M, Wang H, Sang X, Qin M, Bao P, Wang R, Zhang C, Lu H, Li Y, Ren J, Chang H-C, Yan J, Sun Q, Xu J (2018) Sleep and circadian 
abnormalities precede cognitive deficits in R521C FUS knockin rats. Neurobiol Aging 72:159-170. https://doi.org/10.1016/j.neurobiolaging.2018.08.025

42. Zhou J-N, Liu R-Y, Kamphorst W, Hofman MA, Swaab DF (2003) Early neuropathological Alzheimer's changes in aged individuals are

accompanied by decreased cerebrospinal fluid melatonin levels. J Pineal Res 35:125-130. https://doi.org/10.1034/j.1600-079X.2003.00065.x

\section{Publisher's Note}

Springer Nature remains neutral with regard to jurisdictional claims in published maps and institutional affiliations.

Ready to submit your research? Choose BMC and benefit from:

- fast, convenient online submission

- thorough peer review by experienced researchers in your field

- rapid publication on acceptance

- support for research data, including large and complex data types

- gold Open Access which fosters wider collaboration and increased citations

- maximum visibility for your research: over $100 \mathrm{M}$ website views per year

At BMC, research is always in progress.

Learn more biomedcentral.com/submissions 